\title{
OS TIPOS COMPORTAMENTAIS DOS EXECUTIVOS \\ E A POSTURA DO PROFISSIONAL DE SECRETARIADO
}

\section{EXECUTIVES' BEHAVIOR TYPES AND PROFESSIONAL OF SECRETARIAT'S ATTITUDE}

\section{Rosane Fontanella}

Pós graduada em Secretariado Gestão de Pessoas e Processos pelo Complexo de Ensino Superior de Santa Catarina e Sindicato das Secretárias de Santa Catarina - CESUSC/SINSESC

losanef@hotmail.com 


\section{RESUMO}

Depois da revolução tecnológica e da globalização, muitas profissões tiveram um grande crescimento. Como consequência, foram obrigadas a adaptar-se à nova realidade. Dentro desta nova realidade, o perfil do profissional de secretariado evoluiu e se desenvolveu numa trajetória de lutas e conquistas, mudando significativamente. Com a mudança também cresceram as responsabilidades e os desafios. Do desempenho de funções meramente operacionais, o profissional de secretariado passou a pensar e atuar estrategicamente junto a seu(s) executivo(s), conhecendo objetivos, envolvendo-se em projetos e metas. Este trabalho mostra como o profissional de secretariado consegue executar e administrar a sua função ao assessorar executivos com tipos comportamentais tão diferentes. Sinaliza a postura que o profissional de secretariado precisa adotar frente a esses tipos comportamentais e como a utilização de elementos da Inteligência Emocional e da Inteligência Social pode ajudar a criar um ambiente amistoso onde todos possam conviver em harmonia.

Palavras-chave: Profissional de Secretariado; Executivos; Postura profissional; Tipos comportamentais; Inteligência Emocional. 


\section{ABSTRACT}

After the technological revolution and globalization, many professions have had an up and, consequently, they were forced to adapt to the new reality. Within this new reality, the profile of the secretarial professional evolved and developed a path of struggles and victories, changing significantly. With the change it also increased the responsibilities and challenges. Playing purely operational functions, the professional of secretarial began to think and act strategically with their executives, engaging in projects and goals and also meeting these goals. This paper shows how professionals can perform secretarial duties and manage its function to assist executives with very different behavioral types. It indicates the position that secretarial professionals need to adopt towards these types of behavior and the use of elements of Emotional Intelligence and Social Intelligence can help creating a friendly atmosphere where everyone can live in harmony.

Keywords: Secretarial Professional; Executives; Professional attitude; Behavioral types; Emotional Intelligence. 


\section{INTRODUÇÃO}

O presente trabalho tem por finalidade definir os tipos comportamentais dos executivos e a postura profissional do secretário diante dos diversos comportamentos. A importância do profissional secretário é reconhecida através das por meio de competências, conhecimentos, habilidade e atitudes tomadas, e que devem ser considerados no desenvolvimento ou manutenção de sua carreira dentro das estruturas organizacionais.

O perfil do profissional de secretariado no Brasil, historicamente, mudou muito. Atualmente, procura manter sua empregabilidade diante do processo de globalização. Atua como o elo entre clientes internos e externos, parceiros, fornecedores; gerencia informações; administra processos de trabalho; gerencia e organiza sua rotina e a do executivo, para que soluções e decisões sejam tomadas com qualidade. Conquistou vitórias com a mudança significativa do perfil profissional. Além do mais, buscou qualificação e ampliou seu conhecimento na área empresarial e no relacionamento interpessoal, uma vez que participa do processo decisório nas organizações, o que significa pensar estrategicamente.

Diante do engajamento que a administração contemporânea requer de seus profissionais, as competências essenciais à formação de um secretário executivo são: competência técnica, comunicacional e social. Para ser bemsucedido, é preciso aliar o conhecimento, a habilidade e a convivência harmoniosa com as pessoas no espaço profissional, a uma postura profissional coerente, condizente com as regras de conduta que regem o mundo corporativo. (WAMSER, 2010).

Desta forma, por meio deste estudo, pretende-se buscar respostas para o seguinte questionamento: qual a postura do profissional de secretariado frente aos diversos tipos comportamentais dos executivos que assessora e quais os fatores que interferem no relacionamento executivo/profissional de secretariado?

O profissional de secretariado executivo, ao trabalhar em posição estratégica, articulando conhecimento, transformando dados em informações estruturadas e influenciando o processo decisório, revela o seu desempenho na rede de relações interpessoais que administra.

Revista de Gestão e Secretariado, São Paulo, v. 2, n. 2, p.79-104, jul./dez. 2011. 
Sua percepção do ambiente, das pessoas, dos códigos ditos e daqueles implícitos na linguagem não- verbal, o equilíbrio emocional, a visão da empresa como um todo, a criatividade na relação personalizada com o cliente, tudo isso facilitará o dia- a- dia com o executivo, colegas, clientes e fornecedores.

Deste modo, o uso da inteligência emocional pelo profissional de secretariado executivo é importantíssimo pelo fato de seu trabalho ser construído e mantido por uma teia de relações em todos os aspectos, uma vez que suas emoções são as bases que estabelecem a forma de se relacionar com o mundo e determinam o sucesso ou o insucesso de suas atividades.

\section{REFERENCIAL TEÓRICO}

\subsection{TIPOS COMPORTAMENTAIS}

Desde a Antiguidade, pensadores e filósofos vêm tentando classificar e entender as diferenças individuais. Há milhares de anos, os chineses relacionaram as diversas personalidades a doze animais: rato, boi, tigre, coelho, dragão, serpente, cavalo, carneiro, macaco, galo, cão e javali. Eles diziam que cada ano pertencia a um bicho e que a personalidade era determinada por esse animal. Nascia o horóscopo chinês.

Na Grécia Antiga, Hipócrates constatou a existência de quatro humores relacionados à predominância de secreções orgânicas no corpo humano: fleuma, sangue, bílis amarela ou bílis negra. Essa teoria foi mais tarde aperfeiçoada pelo médico romano Galeno, que definiu os tipos como fleumático, sanguíneo, colérico e melancólico, respectivamente. Os fleumáticos são cordiais, gentis e querem agradar aos outros. Os sanguíneos têm o dom da persuasão e da motivação. Entre os coléricos, estão os mais competitivos e determinados. E os melancólicos prezam a organização e a obediência. (BOOG; BOOG, 2004)

Qualquer semelhança dessas categorias com amantes, reis, guerreiros e magos não é mera coincidência, é uma preocupação ancestral do homem: a de compreender a si mesmo e aos outros. A classificação em quatro perfis vem sendo adotada há mais de dois mil anos e serve de referência para modelos 
atuais como os defendidos por Boog e Boog (2004) e pelos especialistas internacionais em comportamento.

Por trás dessas abordagens está a percepção de que os indivíduos têm motivações diferentes e de que há uma espécie de energia individual que move o ser humano. O psiquiatra suíço Carl Gustav Jung dedicou-se ao estudo dessas diferenças comportamentais e percebeu a existência de quatro tipos psicológicos básicos: intuição, sensação, pensamento e sentimento. As categorias propostas por Jung, nos anos 1920, formam a base para boa parte das tipificações que vieram depois dele, inclusive a que percebe as pessoas respectivamente como: reis, guerreiros, magos e amantes. (BOOG; BOOG, 2004)

O guerreiro, de acordo com Jung (apud BOOG; BOOG, 2004), é voltado ao curto prazo, é direto e mais "seco" nos relacionamentos e se baseia muito na razão e lógica. Tem excitabilidade e energias altas. Isso significa que os guerreiros são ótimos para realizar metas. São os "tocadores" e "fazedores"; dentro desta característica os guerreiros têm a tendência ao estresse, sendo workaholics.

Os guerreiros têm o foco no presente, no "aqui e agora", sendo tão voltados às suas tarefas, que tendem a ter dificuldades maiores nos relacionamentos, pois entendem que muita ênfase nos relacionamentos é perda de tempo. São vistos, por isso, como excessivamente diretos, secos e até grossos. São mobilizados pelos órgãos dos sentidos: gostam das coisas materiais que possam tocar, pesar, avaliar, cheirar, medir. Tudo o que não se encaixa nesses critérios sensoriais de perceber o mundo é visto por eles com desconfiança.

O tipo rei é mais voltado ao longo prazo, tem excitabilidade alta e energia baixa. Isso significa que os reis são ótimos indicadores e empreendedores, mas sua grande dificuldade é terminar o que começam. Os reis têm uma visão do tempo mais a longo prazo, situando-se mais no futuro do que no presente. Adoram ser o foco das atenções e gostam de pessoas ao seu lado, principalmente se elas estiverem aplaudindo.

Para Jung (apud BOOG; BOOG, 2004), o rei usa muito seu lado intuitivo, percebendo claramente o sistema como um todo, por isso o rei está sempre em busca de novidades, bastante irrequieto com o estado atual das coisas, quer sempre trazer modificações.

Revista de Gestão e Secretariado, São Paulo, v. 2, n. 2, p.79-104, jul./dez. 2011. 
Os indivíduos do tipo mago são perfeccionistas, meticulosos, organizados, persistentes, críticos, disciplinados, sérios. Eles têm a energia Yin, ajustam-se ao mundo, são mais voltados ao curto prazo, são diretos e secos nos relacionamentos. O mago é o oposto do rei: tem muita energia e baixa excitabilidade. Os magos são ótimos para estruturar e organizar as coisas. São metódicos e tendem ao perfeccionismo. Levam suas tarefas até o fim. Sua visão é de curto prazo. São voltados a colocar ordem nas coisas. São amáveis, mas formais, e relativamente secos nos relacionamentos. Tendem a se isolar, curtindo mais seus momentos de análise que muitos contatos sociais ou festas. Adoram estar certos e têm muito prazer em resolver problemas difíceis e complexos. O mago, quando já se trabalhou em um processo de conscientização e crescimento pessoal, torna-se um possuidor de sabedoria e poder de discernimento, bom senso e clareza de pensamento. (BOOG; BOOG, 2004)

Os indivíduos do tipo amante são cordiais, ponderados, respeitadores, amáveis, harmonizadores, compreensivos e bons ouvintes. Ajustam-se ao mundo, voltados ao longo prazo, são ótimos nos relacionamentos e perfeitos para construir e manter equipes. Pouco metódicos, mas dão um enorme foco às relações.

De acordo com Boog e Boog (2004), o psiquiatra suíço percebeu ainda que as pessoas podem ser extrovertidas se voltadas para o mundo concreto, ou introvertidas, quando preocupadas com valores subjetivos e com o mundo interno. Jung (2002), ao abordar o inconsciente coletivo, defendendo que este é de natureza universal e não individual, pois possui conteúdos e modos de comportamento, corrobora com os estudos voltados ao profissional de secretariado. Para ele, os intuitivos seriam aqueles voltados para o futuro, pessoas criativas e inovadoras. O tipo "sensação" é mais prático e realista. O "pensamento" aprecia a lógica e a organização. E o "sentimento" é regido pelas relações interpessoais.

O desafio de compreender a diversidade humana e aprender a conviver com ela está na ordem do dia das organizações. Os gestores começaram a se dar conta de que trabalhar com equipes mistas pode ser mais eficaz e produtivo do que unir pessoas de comportamento semelhante. É por isso que as empresas estão cada vez mais preocupadas em identificar não só as competências 
técnicas, mas também as diferenças individuais ainda no processo de seleção. (BOOG; BOOG, 2004)

Nesse contexto, segundo Boog e Boog (2004), surgem sistemas como o Human Dynamics, proposto pela psicóloga norte-americana Sandra Seagal. A partir de uma pesquisa com mais de 40 mil pessoas de 25 culturas, ela descobriu que os seres humanos possuem dinâmicas de personalidades diferentes que influenciam desde a maneira de falar até os comportamentos e os valores. Existe aquele tipo que demora a tomar decisões porque planeja tudo a longo prazo. E também há o que está sempre correndo e nunca tem tempo para conversar. Há ainda o mais passional, movido por relacionamentos.

Segundo os autores, a pesquisa identificou três princípios básicos que regem as personalidades: mental, físico e emocional. O modelo tem sido adotado com sucesso para compor equipes e melhorar a gestão de grandes corporações. Não se trata de descobrir se um estilo é melhor ou pior que o outro. Eles são apenas diferentes e isso pode ser muito bom.

\subsection{O COMPORTAMENTO E A INTELIGÊNCIA EMOCIONAL}

Comportamento é o conjunto organizado das operações selecionadas em função das informações recebidas do ambiente por meio das quais o indivíduo integra as suas tendências. De forma prática, segundo Kertész (1987), pode-se definir comportamento como o que se sente, pensa, diz e faz. O que se sente e pensa é o comportamento subjetivo, e o que se diz e faz é o comportamento objetivo. Designa a mudança, o movimento ou a reação de qualquer pessoa ou sistema em relação ao seu ambiente ou situação. São respostas de um organismo às mudanças do meio.

O comportamento deve ser visto como um aspecto constitutivo da espécie humana e como uma relação entre organismo e ambiente. É sempre uma relação ou interação entre eventos ambientais (estímulos) e atividades de um organismo (respostas). A relação organismo-ambiente pode envolver uma situação aparentemente simples ou obviamente complexa. (KERTÉSZ, 1987)

A emoção é uma forma de comportamento, na qual as respostas viscerais condicionadas têm um papel preponderante. Diferente da motivação, nem sempre a emoção tem um objetivo definido. Frequentemente, ela consiste em

Revista de Gestão e Secretariado, São Paulo, v. 2, n. 2, p.79-104, jul./dez. 2011. 
uma reação difusa e desorganizada a algum estímulo interno ou externo. O comportamento emocional é determinado por um complexo jogo de predisposições hereditárias e condicionamentos. (DAVIDOFF, 1983)

Skinner (2000) afirma que existem diferenças entre as pessoas. Elas não reagem todas da mesma maneira a uma dada situação. Contudo, existem algumas consistências fundamentais que sustentam o comportamento de todos os indivíduos, que podem ser identificadas e, então, modificadas para refletir as diferenças individuais.

O comportamento organizacional é o comportamento humano no local de trabalho, a interação entre as pessoas e a organização em si. As principais metas do comportamento organizacional são explicar, prever e controlar o comportamento. Kanaane (2006) acredita que a ênfase no comportamento humano e nas organizações vem sendo um desafio. $O$ comportamento organizacional é vital, pois o fator humano está intrinsecamente vinculado a toda tarefa realizada.

Mas o psicólogo Goleman (1995) leva a uma nova discussão sobre o assunto. Ele traz o conceito da Inteligência Emocional como maior responsável pelo sucesso ou insucesso das pessoas. Segundo seus estudos, $90 \%$ da diferença entre as pessoas que obtêm grande sucesso pessoal e profissional, e aquelas com desempenho apenas mediano, devem-se a fatores relacionados a competências comportamentais.

A maioria das situações de trabalho é envolvida por relacionamentos entre as pessoas. Desta forma, pessoas com qualidades de relacionamento humano como afabilidade, compreensão e gentileza têm mais chances de obter o sucesso. Para Goleman (1995), as pessoas com prática emocional bem desenvolvida têm mais probabilidade de se sentirem satisfeitas e serem eficientes em suas vidas, dominando os hábitos mentais que fomentam sua produtividade. As pessoas que não conseguem exercer algum controle sobre a vida emocional travam batalhas internas que sabotam sua capacidade de se concentrar no trabalho e pensar com clareza em relacionamentos positivos.

A Inteligência Emocional, segundo Goleman (1995), pode ser adquirida, nutrida, desenvolvida e ampliada não se trata de uma característica impossível de adquirir. É preciso que a pessoa tome consciência das competências que 
Os tipos comportamentais dos executivos e a postura do profissional de secretariado

precisa desenvolver e aproveite todas as situações de sua vida pessoal e profissional para praticá-las.

As pessoas que têm desenvolvida a Inteligência Emocional são pessoas com empatia, autoconfiantes, capazes de controlar os impulsos e manter o equilíbrio, não deixando que a ansiedade interfira em sua capacidade de pensar e gerenciar as emoções, o que proporciona relações positivas no ambiente de trabalho.

\subsection{O PROFISSIONAL DE SECRETARIADO}

Os primeiros registros da profissão de secretário datam dos tempos dos faraós, sendo exercida pelo sexo masculino, na figura dos escribas. Após as duas Grandes Guerras Mundiais, a estrutura de mão de obra das indústrias que, até então, era predominantemente masculina, foi modificada, dando início à entrada de mão de obra feminina em funções administrativas, uma vez que a mão de obra masculina estava em combate.

Até metade do século $X X$, a participação da mulher na indústria estava limitada a funções rotineiras e grosseiras. A seguir, as mulheres assumem seus papéis profissionais de uma forma mais liberada, passam a ser reconhecidas por si mesmas e pelo mundo empresarial. Desta forma, os homens se afastam da profissão. Com o surgimento das teorias administrativas, permitiu-se a valorização das funções secretariais, tornando a secretária parte integrante da dinâmica da equipe gerencial.

Em 30 de setembro de 1985 foi sancionada a Lei n 7.377/85 que regulamenta a profissão de secretário. Com a Lei foram estabelecidos os critérios para o exercício da profissão de Técnico em Secretariado e Secretário Executivo. (AZEVEDO; COSTA, 2004)

Para Maerker (1999), o secretariado é uma profissão, e é assim que deve ser visto. A boa secretária, ou o bom secretário, não é aquele que pretende tomar o lugar do líder, mas, sim, aquele que tem vocação para assessorá-lo dentro do que exige uma parceria moderna.

O mercado de trabalho mudou significativamente e está mais competitivo, exigindo profissionais cada vez mais capacitados. Segundo Gil (2001), o capital humano passa a ser entendido como estratégia fundamental para enfrentar as 
transformações radicais. Não são apenas as máquinas e equipamentos que ficam obsoletos; os conhecimentos e as habilidades também. A capacidade de gerar novos conhecimentos e agregá-los ao processo produtivo é que se torna a grande vantagem competitiva.

Dessa forma, o profissional de secretariado teve de se preparar para enfrentar as exigências do mercado. Passou a assumir muito mais compromissos e as suas responsabilidades estão distantes dos serviços burocráticos e rotineiros do passado. Os tempos atuais são marcados pela necessidade de capacitação e estudo constantes. A incorporação de novas competências e habilidades permitiu-Ihe ocupar mais espaço junto aos dirigentes. Tornou-se profissional capaz de intervir, propor soluções para os problemas que surgem no ambiente de trabalho, analisar dados e informações e trabalhar em equipe. (MEDEIROS; HERNANDES, 1995)

Com a maior complexidade das atribuições executivas, o profissional de secretariado, no desempenho de suas atribuições, passou a atuar também como um gerente, solidário à atuação de seu dirigente, no seu nível de responsabilidade. Seus papéis se encaixam, portanto, na classificação dos dez papéis gerenciais propostos por Henry Mintzberg, dentre os quais estão: papel interpessoal (falar em público algumas vezes quando se depara com situações, como representar o seu executivo em alguma reunião); papel de processador de informações (precisa saber disseminar as informações externas para dentro da empresa, como também da informação interna de um subordinado para outro) e no papel de decisão por muitas vezes ter de atuar em situações que estão fora do controle da empresa, tais como os eventos imprevistos, as crises ou os conflitos.

Além de exercer uma influência mais efetiva nas decisões da empresa, é formador de opinião e vem assumindo funções gerenciais. Hoje, atua no processamento e organização de informações advindas do poder decisório. Sua competência técnica o habilita a assumir responsabilidades que demandam iniciativa e autonomia para tomar decisões.

A exigência por uma postura participativa e gerencial aumenta diariamente. $O$ executivo precisa ser assessorado por um profissional atualizado e comprometido, que saiba otimizar as suas competências e desenvolver suas habilidades. É indiscutível que a produtividade do executivo é profundamente 
Os tipos comportamentais dos executivos e a postura do profissional de secretariado

afetada pela maior ou menor habilidade de seu assessor, assim também como a produtividade do assessor é afetada em função de comportamentos dos executivos.

Indiscutível, na atualidade, também é a importância da Inteligência Emocional para o desempenho das funções de um modo geral, especialmente as secretariais. Aplicada ao ambiente de trabalho do profissional de secretariado, possibilita o controle das emoções, proporcionando relações positivas. Tem como resultado a solução de problemas, tomada de decisões acertadas, execução de tarefas com maior eficiência e rapidez e proporciona relações mais positivas e produtivas.

Indispensável que este profissional tenha uma Inteligência Emocional bem desenvolvida para que possa interagir com os executivos que assessora; reconhecimento das próprias emoções, sabendo identificar seus pontos fortes e limitações, aprender com os erros. Indispensável, também, saber lidar com os impulsos e emoções, manter a honestidade e integridade sabendo ser consciencioso, ter flexibilidade para lidar com mudanças e estar aberto a novas ideias.

Empatia é fundamental para perceber os sentimentos, necessidades e preocupações dos demais indivíduos e reconhecer e satisfazer as necessidades dos clientes.

\subsection{POSTURA PROFISSIONAL}

A postura é como um quadro que emoldura uma figura. É como os outros nos veem - em suma, é o conjunto da nossa imagem física e atitude. Para Mussak (2003), postura é a maneira como nos posicionamos perante o mundo, e isso vale tanto para as atitudes corporais e mentais. Devemos ter coerência entre a imagem pessoal e o comportamento, ou seja, parecer ser o que realmente somos.

Se formos competentes devemos deixar isso bem claro por meio de nossas atitudes, ações e palavras. Devemos também ficar atentos ao nosso mundo imediato, ao ambiente sobre o qual podemos interferir.

O grande desafio do profissional de qualquer área de atuação é saber se relacionar bem (tratar as pessoas adequadamente, mostrar-se disponível e 
acessível, ser gentil), ter um comportamento compatível com as regras e valores da empresa e se comunicar bem (fazer-se entender pelos outros, escrever bem, saber ouvir). Apenas a qualidade técnica, porém, não assegura o lugar no mercado.

É fundamental ter sempre em mente que há uma série de atitudes que não estão descritas nos códigos de todas as profissões, mas que são comuns a todas as atividades que uma pessoa pode exercer. Atitudes de generosidade e cooperação no trabalho em equipe, mesmo quando a atividade é exercida solitariamente em uma sala, faz parte de um conjunto maior de atividades que dependem do bom desempenho desta. Uma postura pró-ativa, ou seja, não ficar restrito apenas às tarefas que foram dadas, mas contribuir para o engrandecimento do trabalho, mesmo que ele seja temporário.

Para Medeiros e Hernandes (1995), a profissão de secretário executivo exige principalmente discrição. Muitas informações que Ihe são confiadas, não as pode divulgar. Embora chegue ao seu conhecimento notícias sobre o que acontece em toda a empresa, se quiser manter alto grau de profissionalismo e a estima de todos, deverá manter sigilo sobre tais notícias, principalmente sobre aquelas conhecidas pelo nome de fofoca.

As organizações necessitam de profissionais que redesenhem seus perfis, atualizando suas habilidades para atender às mudanças constantes de uma realidade globalizada. E para atender a essas necessidades, o profissional de secretariado executivo, em sua formação, precisa desenvolver características próprias da profissão, como discrição, bom senso, inteligência emocional, criatividade, resiliência, renovação de tecnologias, controle do fluxo de informações e conhecimentos gerais da área de atuação.

Esse profissional deixa sempre em evidência $o$ fato de que 0 comprometimento de todos os integrantes da equipe está essencialmente relacionado com a satisfação, o que ocorre devido à conscientização, dentre outros, de seu papel de mediador das relações humanas, pois em sua profissão desenvolve uma visão dinâmica do todo. 


\section{METODOLOGIA}

Para o alcance do objetivo, no primeiro momento realizou-se a pesquisa bibliográfica, para se obter o máximo de informações e ampliar o conhecimento da área escolhida e dos conceitos a ela relacionados.

Por se tratar de uma pesquisa exploratória/de campo, foi aplicado um teste em forma de questionário para os três executivos da empresa CNT - que constituíram a população deste trabalho - para identificar os seus tipos comportamentais.

O questionário, intitulado "Como eu sou" e baseado na teoria do psiquiatra suíço e fundador da psicologia analítica Gustav Carl Jung, tendo sido o questionário adaptado por Boog e Boog (2004), era composto por vinte perguntas de múltipla escolha. Cada resposta continha um significado voltado à área de observação da pesquisa, ou seja, baseado no estilo de comportamento do entrevistado/executivo.

Para saber qual o tipo comportamental apresentado pelos pesquisados a partir da aplicação da pesquisa, foi necessário proceder às orientações de Boog e Boog (2004) em relação à pontuação de cada resposta. Após tabular todas as respostas, reportando-se à folha de tabulação sugerida pelos autores supracitados, a soma de cada coluna foi multiplicada por cinco para se chegar ao resultado do perfil dos executivos, caracterizando, assim, uma pesquisa também do tipo quantitativa, por lidar com dados estatísticos.

A análise qualitativa seguiu após a tabulação dos dados a fim de descrever os tipos comportamentais de cada executivo entrevistado na pesquisa a partir dos números apresentados.

Tendo em vista que esta pesquisadora atua na empresa CNT como secretária executiva, também se fez uso da pesquisa de observação participante, que consiste na participação real do pesquisador.

A observação participante é uma técnica muito utilizada na abordagem qualitativa e consiste na inserção do pesquisador no interior do grupo observado, tornando-se parte dele, interagindo por longos períodos com os sujeitos, buscando partilhar o seu cotidiano para sentir o que significa estar naquela situação.

Revista de Gestão e Secretariado, São Paulo, v. 2, n. 2, p.79-104, jul./dez. 2011. 
Segundo Luck, Wales e Taylor (1970), a pesquisa qualitativa combinada ao método de pesquisa quantitativa pode ter bastante utilidade para o estudo de determinados assuntos.

\subsection{LOCAL DA PESQUISA}

A empresa CNT é uma indústria cerâmica situada no sul de Santa Catarina e tem meio século de existência. Teve sua formação inicial através da associação de vários moradores locais onde, com o passar do tempo, um deles foi-se destacando e acabou se tornando o sócio majoritário. Surgia assim uma empresa familiar. A empresa foi crescendo, diversificando sua gama de produtos e hoje possui um grupo de empresas.

Como toda empresa familiar, sofre as influências e divergências de cada gestor, daí a razão pela qual está passando por uma reformulação com o processo para a formação de um conselho de administração.

É uma empresa extremamente enxuta em todos os sentidos. Parque fabril totalmente automatizado, 5,65\% de seus funcionários possuem pós-graduação ou mestrado; $14,35 \%$ possuem curso superior completo, $16,25 \%$ possuem curso superior incompleto, $16 \%$ possuem curso técnico completo, $12,9 \%$ possuem curso técnico incompleto, $34,6 \%$ possuem o segundo grau completo e 0,24\% possuem o primeiro grau incompleto (este índice se refere aos menores aprendizes). As pessoas são multifuncionais e polivalentes executando várias tarefas e responsabilidades ao mesmo tempo.

Seu corpo diretivo é composto por três diretores, a eles estão subordinadas as gerências de áreas, que têm sob sua subordinação os níveis de chefias, sendo supervisão e encarregados de fábrica, respectivamente. A secretária encontra-se no nível de assessoramento, sendo a interface entre a diretoria e os demais departamentos da empresa. 


\section{RESULTADOS DA PESQUISA}

\subsection{PERFIL DOS EXECUTIVOS DA EMPRESA CNT}

Este item apresenta o estudo feito na empresa CNT sobre o perfil dos executivos para saber qual o posicionamento da secretária frente aos diversos tipos comportamentais dos executivos que assessora. Após a aplicação do teste "Como eu sou", identificou-se o perfil de cada um, baseado no estudo dos arquétipos desenvolvido por Carl G. Jung e adaptado por Boog e Boog (2004).

O teste em forma de questionário foi aplicado para cada um dos três executivos da empresa CNT que constituíram a população da pesquisa, com o objetivo de identificar os tipos comportamentais. O questionário era composto de vinte perguntas objetivas; para cada pergunta havia quatro opções de respostas e para cada escolha havia um significado que, ao ser tabulado, de acordo com a tabulação sugerida por Boog e Boog (2004), recebia uma pontuação.

Após tabular todas as respostas reportando-se à folha de tabulação, a soma de cada coluna foi multiplicada por cinco, onde se chegou, desta forma, ao resultado do perfil dos executivos.

A identificação de cada executivo pelas siglas AR, BG e CM foi para omitir suas verdadeiras identidades e nasceu levando em consideração o modo como cada qual é e age no dia a dia corporativo. A letra que os identifica assim é sempre a segunda; a primeira letra de cada um são as três primeiras do nosso alfabeto.

Assim, AR é o Rei porque gosta de reinar, comandar, adora estar no comando da situação. BG é o Gestor, porque além de garantir a funcionalidade e continuidade das tarefas da organização, atende às expectativas dos funcionários e clientes é uma pessoa acessível, aberta. Já CM foi denominado como Mentor por ser uma pessoa com uma idade mais avançada e trazer em seu currículo uma grande experiência de vida e, ainda, ampla visão estratégica. É a ele que os outros executivos recorrem quando necessitam de aconselhamento para um novo plano de ação ou um novo empreendimento.

Levando em consideração que cada pessoa em sua essência compreende um conjunto de sentimentos, ações e reações, a seguir serão apresentadas algumas das características que definem cada executivo a partir da tabulação 
dos resultados do teste aplicado e considerando os tipos comportamentais apontados no estudo dos arquétipos desenvolvido por Carl G. Jung e adaptado por Boog e Boog (2004). Em seguida, será analisada a postura do profissional de secretariado frente a estes tipos, com base em fundamentos teóricos e, em nossa experiência como secretária, no assessoramento a estes três executivos pesquisados.

\subsubsection{O Executivo AR}

De acordo com os perfis definidos no item 2.1, o executivo AR identificouse com os perfis Guerreiro e Rei.

Ao aplicar o teste/questionário e depois de feita a tabulação, verificou-se que o executivo AR é uma mistura dos dois tipos comportamentais descritos acima. Analisando o seu comportamento e suas atitudes no dia a dia, pode-se verificar que ele é hiperdireto, quando tem algo a dizer fala diretamente, é considerado seco nas palavras, muitas vezes sendo até grosseiro com as pessoas ao seu redor. O executivo AR é extremamente movido pelos órgãos do sentido.

Quando alguém for solicitar algo deve levar todas as informações e relatórios e muitas vezes já apontar a solução. Tudo deverá estar no papel, para que ele possa analisar e enxergar os números, só isso o fará dar um parecer, tomar alguma decisão. Se for apresentar argumentos sem dados palpáveis é pura perda de tempo. Herdou do Rei o foco das atenções, os aplausos e a tirania. Como a própria palavra já nos remete à autoridade, assim ele é. Usa essa autoridade muitas vezes para amedrontar e fazer prevalecer sua opinião.

Ao lidar com o tipo comportamental como o Executivo AR, como profissional do secretariado e pelo fato de estarmos ao seu lado no dia a dia assessorando-o diretamente em todas as demandas que tiver, nossa postura está, acima de tudo, pautada na prudência ao lidar com ele. Como ele é excessivamente "explosivo", de nada vai adiantar "bater de frente", mesmo que ele não tenha percepção do impacto de seu comportamento sobre as pessoas da empresa que interagem com ele. Claro, isto nem seria uma postura adequada de uma secretária executiva. Ao contrário, muitas vezes, batemos em retirada e, quando for oportuno, voltamos e abordamos aquele determinado assunto que 0 fez agir explosivamente. 
Entendemos que, como secretária, devemos compreender o contexto, para então podermos compreender o comportamento de uma pessoa, como Albrecht (2006) deixa claro ao se referir à consciência situacional. A leitura clara do contexto permite-nos conhecer os códigos de conduta que são praticados no ambiente. E neste caso, mais precisamente diante do executivo $A R$, é preciso saber se portar e comportar, seguindo regras de conduta que envolvem desde a aparência física até a maneira de adentrar em sua sala.

Requer de nós uma postura física ereta, convincente, confiável, já que prefere lidar com profissionais voltados para a solução. Talvez uma profissional do secretariado sem o entendimento do contexto e imatura emocionalmente, ao assessorar um executivo AR, tenha certa dificuldade de transmitir, por intermédio de sua postura física, confiança e profissionalismo. Pelo contrário, acabaria comunicando-Ihe insegurança, timidez, indiferença.

Além disso, cabe-nos na condição de sua secretária preservar a imagem deste executivo, já que perante o grupo ele é visto como autoritário, amedrontando seus subordinados. Como interface constantemente intermediamos e facilitamos a comunicação entre eles. Usamos nossa habilidade comunicacional para incentivar outros diretores e gerentes a não terem receio de se relacionar com ele (AR). Temos certeza de que o conhecimento que temos do contexto organizacional em que estamos atuando e o uso de nosso senso de diplomacia privilegiam-nos a sempre encontrar o momento oportuno para que o diretor e seus subordinados tenham uma conversa agradável.

\subsubsection{O Executivo BG}

O executivo BG identificou-se com o perfil Guerreiro e Mago. Herdou do guerreiro as metas a curto prazo, não teme obstáculos. Um pouco seco e direto nos relacionamentos, porém o seu lado mago o transforma numa pessoa amável, mas formal. Perfeccionista, porém prático, tem um relativo fascínio por resolver problemas complexos. Pessoa de bom senso, discernimento e clareza.

Trabalhar com este executivo não é complicado, pois ele é bastante prático e, de um modo geral, as coisas fluem. O problema é conseguir um horário na sua agenda, visto que está sempre correndo contra o tempo. Ele assumiu o cargo de Diretor há pouco tempo, por conta da reestruturação que está sendo implantada, o que o levou a ter de assumir muitas responsabilidades. Como não o 
assessorávamos diretamente antes, ainda estamos na fase de conhecê-lo melhor, assim como ele também está aprendendo a trabalhar com um profissional do secretariado. Contudo, sabemos que o foco principal no momento é organizar o tempo dele (BG), que é um fator relevante a ser corrigido de imediato para que não afete o desenvolvimento e crescimento dele e da organização.

Entendemos que aqui o papel da secretária se torna aparentemente mais fácil já que o executivo em questão é uma pessoa dinâmica e entusiasta. Pessoas assim tornam o ambiente mais leve, fazendo com que a secretária fique mais motivada e busque constantemente superar-se e promover novas ações. Mas não podemos nos esquecer do fator "tempo" que é de extrema importância para o executivo, cabendo à secretária gerenciá-lo eficazmente.

É fazer a gestão do tempo, serviços e informações do executivo para que ele não tenha interrupções e assim consiga direcionar o seu tempo para os objetivos da empresa, focando nas atividades verdadeiramente importantes, ou seja, aquelas que trazem resultados efetivos. Mais uma vez, contatamos quão fundamental é o papel da secretária em saber dizer "não" e filtrar todos os assuntos que permeiam esta situação para que o executivo possa dedicar-se por inteiro ao foco de suas ações. No mundo corporativo, os executivos procuram profissionais em quem possam confiar e trazer resultados. Sabemos que possuímos poder e autoridade, então precisamos fazer e fazer acontecer.

\subsubsection{O Executivo CM}

O executivo CM não teve um perfil destacado para um determinado tipo comportamental. É uma mistura de Rei, Guerreiro, Mago e Amante. Do Rei herdou a intuição, o empreendedorismo e a facilidade de relacionar-se. Do Guerreiro, a impaciência; do Amante, a cordialidade e ser um bom ouvinte, gosta de ouvir a opinião da equipe e a incentiva a criar e opinar. Do Mago herdou um pouco da paciência e autocrítica.

Sendo este executivo uma mistura dos quatro perfis, existem altos e baixos. Há momentos em que é amável e em outros, é impaciente; outras vezes incentivador e em outras, extremamente crítico. A secretária precisar estar alerta diariamente para saber como agir naquele dia. 
Digamos que seria como se adaptar às condições climáticas. Muitas vezes a manhã está linda e no meio da tarde aparece uma nuvem cinzenta e precisa se recorrer a uma capa e um par de botas porque o tempo mudou repentinamente. Assim é trabalhar com este executivo (CM).

O problema não é nada com a secretária, no entanto, precisamos ter muita paciência e fazer o papel de psicóloga, saber ouvir, ponderar, opinar e muitas vezes mostrar a direção. E outras vezes, porém, precisamos ser firmes e fazer de conta que realmente o assunto não é conosco como secretária; é dar meia volta e retornar às atividades. Do contrário entendemos que seremos "abduzidos" por coisas e fatos que só irão "roubar" nosso precioso tempo e nada irão acrescentar ao dia a dia, serão por mero capricho.

Porém, o dia em que ele está bem, é compreensivo, tolerante, gosta de conversar, e é só dar-lhe atenção que é provável que fique horas a versar sobre assuntos diversos e principalmente sobre sua história de vida.

Podemos perceber que trabalhar com um profissional igual a este não é tarefa fácil, já que ele apresenta mudanças de humor/comportamento que vão de oito a oitenta. Como profissionais sábias usamos nossa flexibilidade, resiliência, diplomacia e, acima de tudo, atitude e intuição para que esta relação possa ser produtiva. Na condição de facilitadora e seguindo os princípios da administração: tomando decisões, solucionando conflitos e trabalhando em equipe, cada vez mais, precisamos estar aptas a agir diante de situaçõesproblema que surgirem.

\subsection{DISCUSSÃO DOS RESULTADOS}

O uso da Inteligência Emocional é fator crucial para o bom desempenho profissional. Ordenar, transmitir e entender informações e experiências são ações vitais para o sucesso e para o bem-estar das pessoas. Usando a Inteligência Emocional, as possibilidades de que portas se abram no relacionamento profissional são muito maiores, comparando com o profissional incapaz de viver ou de entender as emoções e sentimentos de seus companheiros de trabalho.

A teoria da Inteligência Emocional demonstra que os sentimentos seguem uma lógica precisa e introduz uma ferramenta poderosa para uma comunicação 
efetiva no ambiente de trabalho. Segundo Simionato (2006), alguns elementos relevantes da Inteligência Emocional para uma comunicação efetiva são: consciência emocional; controle emocional; capacidade de saber motivar-se; capacidade empática; e a gerência eficaz das relações interpessoais e habilidade social.

Para Albrecht (2006), Inteligência Social é a habilidade de se relacionar bem com outras pessoas e conquistar sua cooperação. Precisamos ser cada vez mais socialmente competentes para estabelecer uma sociedade mais humanizada, para evitar a desarmonia do ambiente de trabalho, para aprender a lidar com pessoas nocivas ou saber o momento de se afastar.

Ter Inteligência Social ajuda o profissional de secretariado a ter condições de fazer sua parte para transformar o ambiente de trabalho em um lugar melhor, mais harmônico, mais saudável, além de proporcionar espaço para a criatividade, a inovação e a opinião.

O profissional de secretariado deve ser um bom comunicador, utilizandose dos conhecimentos da Inteligência Social. Essa habilidade engloba, entre outras qualidades, autenticidade, clareza e empatia, fatores determinantes para o crescimento pessoal, profissional e intelectual.

A comunicação está intrinsecamente ligada à Inteligência Social e à Inteligência Emocional, que são conceitos fundamentados por especialistas das relações humanas e que abordam aspectos do autoconhecimento, alinhando técnicas de aperfeiçoamento.

Como a secretária pode assessorar executivos com tipos comportamentais tão diferentes? Digamos que entendê-los, compreendê-los, amá-los ou odiá-los requer mais que uma dose de paciência ou vontade. Requer que o profissional de secretariado primeiramente queira trabalhar todas essas diferenças para que o relacionamento entre eles traga resultados satisfatórios. É necessária muita Inteligência Emocional e Social.

As emoções desempenham um papel importante na comunicação no local de trabalho. Segundo Weisinger (1997), o truque é usar as emoções de maneira inteligente: fazer intencionalmente com que as emoções trabalhem em seu benefício, usando-as para ajudar-se a orientar seu comportamento, seu raciocínio (e sua forma de comunicação) de maneira a obter melhores resultados. 
De qualquer forma, no entanto, é relevante lembrar que uma comunicação efetiva implica escutar atentamente o outro, usando a Inteligência Emocional. O escutar ativo implica: postura corporal de escuta; interrupção do que se faz para escutar; olhar para o interlocutor; usar palavras indicativas de compreensão ou sinalizar silenciosamente com um pequeno movimento da cabeça; evitar julgamentos e avaliações e, finalmente, empatia.

Conhecer os tipos de líderes requer tempo, paciência e uma Inteligência Emocional aguçada para conseguir decifrar e entender todos os enigmas que envolvem cada ser que assessora.

Depois de muito tempo assessorando os mesmos executivos a confiança é adquirida. Podemos dizer que se assemelha a um casamento; com o tempo se vai descobrindo quem é quem. Aí começa a ser criada uma simbiose, onde um passa a conhecer o outro mais profundamente e a secretária consegue antecipar os imprevistos, resolver os assuntos de forma muito mais ampla, com muito mais consciência da importância do seu trabalho e passa a entender dos projetos e negócios da empresa.

A Inteligência Emocional, aplicada ao ambiente de trabalho do profissional de secretariado, possibilita o controle das emoções e proporciona relações positivas. É indispensável que o profissional tenha uma Inteligência Emocional bem desenvolvida para que possa interagir com os executivos que assessora. Ter o reconhecimento das próprias emoções, sabendo identificar seus pontos fortes e limitações, aprender com os erros.

O profissional de secretariado precisa saber lidar com os impulsos e emoções, manter a honestidade e a integridade, ser consciencioso, ter flexibilidade para lidar com mudanças e estar aberto a novas ideias. Deve manter a calma quando o caos prevalece e sempre pensar de forma ponderada quando os que o rodeiam não podem.

Do ponto de vista específico de comunicação dentro de uma empresa moderna, no entanto, o espaço dedicado à expressão das emoções é muito reduzido. A esfera emotiva é quase sempre colocada completamente fora do ambiente de trabalho. Todavia, no mundo moderno, começa a se tornar cada vez mais clara a necessidade de um novo paradigma que inclua a administração conveniente das emoções no local de trabalho. O uso correto da comunicação 
baseada na leitura do estado emocional do interlocutor é, hoje, essencial em todas as empresas.

As pessoas são muito diferentes umas das outras, em sua forma de pensar, agir e interagir; porém essas diferenças são necessárias para o crescimento e desenvolvimento da empresa. Sabe-se que não há relacionamento sem conflito. Por isso, a questão está em adquirir competência para enfrentar este conflito, para que este seja produtivo para ambas as partes. É preciso melhorar as competências emocionais, técnicas e gerenciais para que secretária e executivo, com seus diferentes tipos comportamentais, obtenham sinergia e que esta seja produtiva com qualidade de vida.

Fazendo referência aos executivos aqui pesquisados, podemos dizer que as suas diferenças complementam o todo. De acordo com Maerker (1999), trabalhar ao lado de alguém significa aprender a conhecer o outro e a respeitar seu modo de ser. Agir com honestidade, ter conduta ética pautada em sólidos valores morais e saber gerenciar as emoções diante dos diferentes tipos comportamentais de executivos que assessora, cria em torno do profissional de secretariado um ambiente harmônico, de confiança e estruturado na verdade.

\section{CONSIDERAÇÕES FINAIS}

O cenário empresarial impõe cada vez mais mudanças por causa dos efeitos da globalização e da transformação diária das ferramentas tecnológicas. Com isso, há uma maior exigência nos processos de seleção e contratação do profissional de secretariado.

Secretariado Executivo é uma profissão que vem crescendo ao mesmo tempo em que o desenvolvimento humano e tecnológico também se sobressai, sendo esses dois itens necessários nas organizações. Contudo, tal progresso, além dos benefícios, traz consigo as exigências de comportamentos e atitudes, através de novas formas de lidar com dados que exigem controle emocional na inter-relação com o(s) executivo(s) da organização e com o público em geral.

Cabe ao profissional demonstrar as mudanças ocorridas na área de secretariado, por meio de uma postura diferenciada e comprometida com os resultados da empresa. 
Assim, o profissional de secretariado assume maiores responsabilidades compatíveis com a sua importância, exercita a liderança, utiliza a criatividade, a comunicação, o equilíbrio emocional e adquire capacidade de assessorar e exercer o papel de cogestor nos processos decisórios, utilizando os recursos tecnológicos a seu favor.

Finalizamos este estudo com os objetivos plenamente atingidos. Foi possível concluir que as pessoas são extremamente diferentes umas das outras, em sua forma de pensar, agir e interagir; porém essas diferenças são necessárias para o crescimento e desenvolvimento da empresa.

Conforme neste estudo já citado, atualmente vê-se a diversidade comportamental como algo positivo nas organizações, podendo esta enriquecer os trabalhos desenvolvidos, trazer benefícios às empresas - diferentemente de como se acreditava anteriormente que somente tendo pessoas que pensassem de modo igual os resultados aconteceriam.

Fazendo referência aos executivos aqui pesquisados, mesmo sendo estes apenas uma amostra do que existe nas organizações, podemos dizer que as suas diferenças complementam o todo, ou seja, as empresas precisam do rei porque ele é empreendedor, do guerreiro porque ele é fazedor/tocador do projeto, do mago para estruturar e organizar e do amante para construir e manter equipes - um completa o outro.

Uma organização formada só de reis não teria êxito, haveria muitos empreendedores e faltariam aqueles que tocassem o projeto, organizassem e formassem equipes. O ideal é que as organizações tenham os quatro tipos comportamentais definidos em seus executivos.

Cabe ao profissional de secretariado usar de suas competências técnicas e comportamentais, sua Inteligência Emocional e Social para conhecer profundamente os executivos que assessora. Desta forma estará trabalhando para que seja um time de sucesso, trazendo excelentes resultados para a tríade empresa/executivo/secretário. 


\section{REFERÊNCIAS}

ALBRECHT, K. Inteligência social. São Paulo: M. Books do Brasil, 2006.

BOOG, Gustavo; BOOG, Magdalena. Conviver em equipe: construindo relacionamentos sustentáveis. 2. ed. São Paulo: M. Books do Brasil, 2004.

BRADBERRY, Travis; GREAVES Jean. Desenvolvendo a Inteligência Emocional. Rio de Janeiro: Sextante, 2007.

GOLEMAN, D. Inteligência emocional. Rio de Janeiro: Objetiva, 1995.

JUNG, Carl Gustav. Os arquétipos e o inconsciente coletivo. 4. ed. São Paulo: Vozes, 1921.

KANAANE, Roberto. Comportamento humano nas organizações: o homem rumo ao século XXI. 2. ed. São Paulo: Atlas, 2006.

KERTÉSZ, Roberto. Análise transacional ao vivo. São Paulo: Summus Editorial, 1987.

MAERKER, S. Secretária: a parceria de sucesso. São Paulo: Gente, 1999.

MEDEIROS, João Bosco; HERNANDES, Sonia. Manual da secretária. São Paulo: Atlas, 1995.

MUSSAK, Eugenio. Metacompetência: uma nova visão do trabalho e da realização pessoal. 2. ed. São Paulo: Gente, 2003.

SIMIONATO, M. Competências emocionais: o diferencial competitivo no trabalho. Rio de Janeiro: Qualitymark, 2006.

WAMSER, Eliane. A secretária que faz. Blumenau: Nova Letra, 2010. 
Os tipos comportamentais dos executivos e a postura do profissional de secretariado

WEISINGER, Hendrie. Inteligência Emocional no Trabalho. 12. ed. Rio de Janeiro: Objetiva, 1997.

Data do recebimento do artigo: 25/07/2011

Data do aceite de publicação: 11/11/2011

Revista de Gestão e Secretariado, São Paulo, v. 2, n. 2, p.79-104, jul./dez. 2011. 